\title{
Building Strategic Business Partnerships With Software Vendors: A Best Practice Model For Behavioral Health \& Social Service Organizations
}

J. Jay Mackie, Shippensburg University, USA

Monica E. Oss, OPEN MINDS, Gettysburg PA, USA

\begin{abstract}
Deployment of emerging technology holds great promise to improve the operation of organizations in the behavioral health and social service field. New technology can reduce operating costs, improve service quality, and enable new service offerings, providing strategic advantage in an increasingly competitive market. With increasingly strategic implications of technology in the field, it is important that managers understand the importance of choosing technology vendors that will be not just a supplier, but a strategic business partner. Among the many technology vendors, strategic relationships with software vendors are key. Software selection is an important and often underestimated process that holds the key to developing these strategic business partnerships. In the current market, it is not unusual to find many software vendors offering a wealth of functionality in their applications at a wide range of price points. Traditionally, managers in the field have selected a software vendor with a simplistic value equation of the amount of functionality per dollar spent, with an assumption of fixed useful life of the software product. However, as the health and human service field has become more competitive and more dynamic, the ability to work with the software platform and the software vendor to collaboratively and quickly meet those needs is a key to maintaining strategic advantage. This article outlines a 'best practice' in software selection process that builds the framework for creation of such a strategic partnership with a software vendor - a selection process that weighs software functionality and price, but adds the dimension of vendor responsiveness to the equation.
\end{abstract}

Keywords: Technology; Software Selection; Vendor Partnership; Behavioral Health; Social Services

\section{INTRODUCTION}

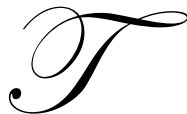

echnology, in general, and software in particular, are strategic issues for behavioral health and social service organizations. U.S. spending on this niche of the health and human service field - which includes mental health services, addiction treatment, child welfare, juvenile justice, disability supports, and related services - is over $\$ 200$ billion per year. ${ }^{12} 345$. Like other areas of health and human services, there is tremendous pressure on policymakers to contain or reduce spending - and corresponding pressure on managers of service provider organizations to serve more people with no increase in budgets. ${ }^{6}$ Deployment of new technology - from electronic health records to automated billing systems, to web-based consumer self-service tools - is one area for management teams to achieve economies of scale and add new service delivery capabilities, while potentially reducing costs and improving quality. ${ }^{78}$

The technology options - and the pending technology-related mandates - for management teams in the behavioral health and social service field are extensive. ${ }^{9}{ }^{10}$ Enterprise software systems that automate data recording 
for client recordkeeping, billing, outcomes measurement, and mandated compliance reporting have been of particular interest over the past five years. Increasing complexity of billing requirements has increased the value of automated billing systems. ${ }^{11}{ }^{12}$ Consumer-focused service delivery has increased interest in on-line consumer functionality - for both service delivery and for service support functions like scheduling and personal records.

Along with the emerging technology options, new regulatory requirements are adding to the technology mix. Government requirements for patient confidentiality have mandated protections to patient records that are often only possible with automated systems. ${ }^{13}$ Pending government mandates for interoperable patient records will increase the need for state-of-the-art patient recordkeeping software systems. ${ }^{14}$ How management teams assess, select, and deploy new technologies is a key to strategic advantage in an increasingly competitive marketplace. Of the pending new technology acquisitions, selection of software is the most immediate management issue due to a combination of increasing system complexity, pending system mandates, and the need to create competitive market advantage.

\section{SOFTWARE DEPLOYMENT IN THE FIELD \& TRADITIONAL PROCESSES FOR SOFTWARE VENDOR SELECTION}

The health and human service field in general, and the behavioral health and social service field in particular, does not have a history of successful software deployment. Despite the current and future demands outlined above, these organizations have tended to be slow to purchase new software. Their management teams often fail to properly assess the information management requirements that will lead to purchasing software that will be optimal in meeting organizational needs. ${ }^{15}$ And, even when new software is purchased, success rates are low on implementation of software projects due to specification/software mismatch; a frequent unwillingness to change established service processes to incorporate new system capabilities; and limited deployment of change management processes. ${ }^{16}$

There are two common causes of poor software vendor selection in the field - (1) a less-than-systematic approach to identifying current and future software functionality needs and (2) a limited model for selecting software vendors. With regard to developing a thorough inventory of functional needs from any new software systems, managers should use a structured process for evaluating current functionality needs (and creating a gap analysis of their current system functionality). In addition, managers should apply the same structured process to the organization's future functionality needs, typically as part of the organization's strategic planning process. ${ }^{17}$ Having a complete picture of both current gaps in system functionality and future functionality needs provides a basic framework for starting the software vendor selection process.

But even the most comprehensive analysis of current and future system functionality needs can be rendered useless by limited vendor selection models. In many health and human service organizations, the software vendor selection process is made on a commodity-like model with the selected software vendor as the one that offers the most proffered functionality for the lowest cost. This model was adequate when the only software purchases made by organizations in the field were to support low-cost back office administrative operations. However in today's market, software affects all aspects the delivery of health and human services, and has a fundamental impact on the provider organization's interface with the consumer. Many managers fail to realize that new software offers the potential benefit of reevaluating and reengineering service delivery processes. ${ }^{18}$ And, increasingly, managers are finding that planned service line expansions are precluded by the inability to expand organizational information management capabilities using existing software.

The key is to bridge the gap from commodity approaches to software vendor selection to an approach that seeks a vendor to fill the role of strategic technology partner. It is critical that managers view software vendor selection as "business change" projects, requiring the partnering of executive management and the information systems management units to ensure that technology projects are more likely to succeed. ${ }^{19}{ }^{20}$ With this strategic business change focus, managers can be better prepared to address the needs of the organization and make better decisions regarding the appropriate software vendor. This is particularly critical for smaller behavioral health and social service provider organizations that typically do not have the extensive information systems staff. These organizations are particularly reliant on the software vendor to provide not only basic functionality but also strategy 
advice and support. The methodology and process outlined below is a first step in a software vendor selection process that facilitates building strategic business partnerships between customer and vendor organizations.

\section{FOUR CORE SOFTWARE VENDOR EVALUATION FACTORS}

In the traditional commodity-focused value equation for software selection, managers used the basic measure of the amount of functionality compared to system cost as the equation for selecting software. This value proposition could be expressed as:

\section{Functionality}

Total Software Acquisition Cost

However, this simple equation does not factor in the ability of the new software to reduce costs through reengineering. To add the cost-offset due to reengineering into the equation, the revised value proposition could be portrayed as follows:

\section{Functionality}

(Total Software Acquisition Cost) - (Organizational Cost Savings)

Finally, the decision-making model should be modified to incorporate the value of the software vendor as a strategic partner in responding to future market changes. This model could be represented as:

\section{Functionality + Customer Responsiveness}

\section{(Total Software Acquisition Cost) - (Organizational Cost Savings)}

In this proposed model that is focused not only on technology functionality, but also strategic partnerships, we recommend that managers evaluate software vendors based on four core evaluation factors: functionality, organizational cost savings, customer responsiveness, and total acquisition cost.

Software functionality is defined as how well the vendor's product meets the specific business needs of an organization. To evaluate this properly, managers need a clear understanding of what functionality is available in the marketplace, as well as a detailed understanding of the organization's business needs and operational goals - both now and in the future. The organization's executive team and its current information systems staff should be able to provide a basic inventory of functionality that can be used in discussions with potential vendors.

Organizational cost savings is essentially the 'savings' component of standard return-on-investment (ROI) analysis - those savings to an organization that will result from reengineering service delivery and administrative processes with software. ${ }^{21}$ There are a number of factors that can contribute to organizational savings from new software including reduced labor costs through automation of processes; additional revenues through increased productivity; reduced compliance or accreditation costs, and improving collections rates and turnaround times.

Customer responsiveness is complex. It can include a variety of factors - a vendor's track record in training and implementation; the satisfaction of similar organizations with the vendor's products and related service; the vendor's responsiveness to enhancement requests and market demands, timeliness of help desk support, and/or rapid problem resolution. It incorporates the notion of the vendor as a partner, rather than that of simply a supplier of goods.

The last area is total acquisition cost. Note that this phrase is "total cost" and not just "price." The price of software is only one element of the total cost. In the current marketplace, new models of pricing have emerged, including "leasing"-type models where purchasers pay monthly fees for software and services rather than purchase 
software licenses. Additionally, some vendors offer ASP's that will host the application and databases for a fee. In assessing total cost, software price is considered along with maintenance fees, customization costs, installation costs, training costs, implementation costs, speed of implementation, and more. This expanding definition of "cost" also reflects the more complex role of technology. When evaluating vendors in this area, it is helpful to develop a threeto five-year budget for each vendor - including any technology upgrades and staff enhancements needed - so that managers can accurately compare the total potential organizational costs.

While all four of these factors should be given consideration in making this decision, it is important to understand that these areas of evaluation may not be the sole measures in selecting a software vendor. A discussion among executive team members and information systems team members is necessary to determine the weighting of the factors for the organization at this particular point in time.

\section{A BEST PRACTICE SOFTWARE SELECTION PROCESS}

To operationalize this vendor evaluation model, we recommend a nine-step approach when reviewing software vendors and selecting a software application:

- $\quad$ Step \#1: Identify current/future required and desired software functionality

- $\quad$ Step \#2: Develop and release a request for proposal

- $\quad$ Step \#3: Conduct preliminary vendor screening based on knock-out factors

- $\quad$ Step \#4: Conduct a survey of current vendor customers to gauge customer responsiveness

- Step \#5: Analysis of vendor functionality and total cost

- $\quad$ Step \#6: Estimate differences in organizational cost savings between vendor software solutions

- Step \#7: Conduct software demonstrations and select finalists by focusing on functionality "fit"

- $\quad$ Step \#8: Conduct additional research and evaluation on vendor to make a final selection

- $\quad$ Step \#9: Contracting and software implementation

Step \#1: Identify Current/Future Required \& Desired Software Functionality One of the keys to successfully selecting a software application is knowing what functionality the organization needs. Most organizations understand this concept and start this process by defining functional needs based on current operations. They identify opportunities for automation, enhanced reporting, and information sharing, as well as deficiencies in the current information system. However, this process should also try to determine the potential needs of the organization going forward in this frequently changing technological environment. Future functionality needs should be determined based both on the organization's strategic plan and a comprehensive understanding of what functionality is available in the marketplace. This enables the executive team to identify opportunities to maximize the use of technology for competitive advantage.

For this reason, the first step in the software selection process has three components: a gap analysis of current functional needs versus capabilities, an assessment of future functionality needs based on the organization's strategic plan, and an overview of what new products and services are available in the market place. The last item can be accomplished by attending trade shows where vendors exhibit, requesting marketing and promotional materials from vendors, or sometimes even issuing a request for information to gather basic information about functionality and services. The goal is not to evaluate the vendors, but rather to gain a better understanding of available technologies.

Conducting an assessment of current and future functional needs requires a detailed review of current operations and identification of software support needed by the key functions, as well as a similar assessment of future operations outlined in the strategic plan. To develop a gap analysis, current functional needs are compared to current system capabilities. The result of this phase is a functional needs specification document that outlines current and future functional needs of the organization and presents a "gap analysis" of current information systems functionality. 
While the exact functional specifications may vary from organization to organization, there are common areas of functionality that should be reviewed to determine which specifications are most important. These broad categories include:

- $\quad$ Consumer and staff demographic and billing data

- $\quad$ Scheduling and eligibility verification support

- $\quad$ Service delivery data

- $\quad$ Service billing capabilities - fee-for-service, per diem, inpatient, case rate, and/or capitated contract billing

- $\quad$ Accounts receivable management

- $\quad$ Electronic medical/case record functionality

- $\quad$ Clinical decision support and outcomes management

- $\quad$ Staff alerts, messaging, and tickler systems

- $\quad$ System security functionality

- $\quad$ Report writing functionality

- $\quad$ Point-of-service system access

In addition to these standard service delivery supports, there are categories of functional needs that are specific to the types of services an organization delivers:

- $\quad$ Consumer self-service and personal health information

- $\quad$ Resourced-based appointment scheduling

- $\quad$ e-health functionality

- $\quad$ Foster and adoptive family tracking, licensing, and payment-based staff support tools

- $\quad$ Volunteer matching and tracking

- $\quad$ Service authorization and claims adjudication and payment

- $\quad$ On-line training and credential tracking

- $\quad$ Network provider management

- $\quad$ Prescription and pharmacy management functionality

Step \#2: Develop \& Release a Request for Proposal The second step is to incorporate the organization's functional needs into a request for proposal (RFP). The RFP should specify the structure and content of the responses that the management team would like to receive, typically including the following components:

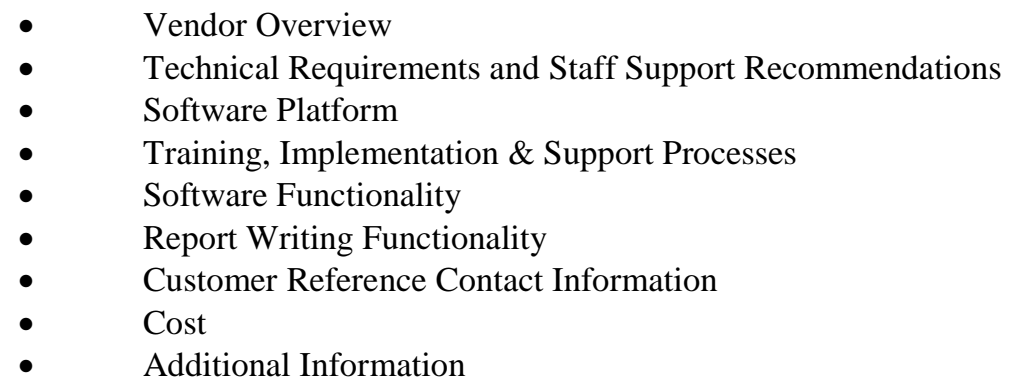

For the vendor overview, ask the vendor to describe its company, customers, and services, as well as what key qualifications they can offer to meet the organization's technology and information management needs. This information provides a basic understanding of the vendor's business. The overview should also ask for vendor financial information.

With regard to technical requirements and staff support recommendations, request that the vendor describe the hardware, software, network, and telecommunications set-up needed or recommended for its technology solution. This information lets the information technology team know what infrastructure is needed to support the vendor's product - a critical piece of information in developing total cost estimates. The RFP should also ask the 
vendor for recommended staffing to support the application once it is up and running. In addition, ask the vendor to describe the software platform and/or databases used by its technology solution and any near-term plans for upgrade, if applicable.

Training, implementation and support processes are vital to a successful software implementation and a key to future strategic partnerships with the vendor. In the RFP, request a description of the vendor's typical approach to training and implementation, as well as how it provides customer support. Specifically, request an implementation plan with an itemized list of activities, estimated manpower, and a timeline. This implementation information provides a better understanding of the time and level of effort needed to successfully implement the vendor's technology solution.

A crucial part of successful technology development is matching software functionality to the organization's need. In the RFP a list of functional specification needs should be provided and the vendor should describe their ability to meet each functional specification. In addition, ask responding vendors to describe the report writing capability of its technology solutions, including a listing and description of standard reports and export capabilities. To evaluate and characterize the vendor's relationships with other organizations, request a list of at least 25 current customer organizations that could be contacted in a survey. Also ask the vendor to highlight those customers who are most satisfied with its products and services and/or those whose needs are most similar to those requested in the RFP.

With regard to cost, ask the vendor to detail the cost of its software technology solution. This information should clearly distinguish between one-time and on-going costs and be complete enough (along with the information from the Technical Requirements section) to develop a three to five-year budget for the proposed solution.

Step \#3: Conduct Preliminary Vendor Screening Based on Knock-Out Factors Once the responses from the software vendors have been received, the initial evaluation process can start with scoring the vendors on how well they meet the stated functional needs. For this preliminary screening of vendors, it is useful to use "knock-out" factors that are driven by the organization's business needs and management and purchasing choices. Potential "knock- out" factors include the following:

- $\quad$ Software price and other cost factors

- Lack of "mission critical" functionality

- $\quad$ Vendor size and customer base

- $\quad$ Vendor experience with specific local market or specific service type(s)

- $\quad$ The vendor's software technology platform and database

- Whether the vendor has or requires a hosting or offers an application service provider option

- Whether the vendor offers wireless or disconnected database technologies

By creating a list of knock-out factors, managers can greatly reduce the vendor evaluation time required by eliminating vendors that are not optimal.

Step \#4: Conduct Current Customer Service Reference Checks to Gauge Customer Responsiveness The next step is to conduct reference checks for the remaining vendors to measure customer satisfaction and service. Make a point to contact at least ten references for each of the vendors. Consideration should be given to eliminating vendors who score poorly in the reference checks, but do keep in mind that good or bad customer service cannot be concluded from a single good or bad reference. The field is full of great software, poorly implemented.

Step \#5: Analyze Vendor Functionality \& Total Cost Take the time to develop a three- to five-year budget for each of the vendors (including any required technology infrastructure upgrades and changes in staffing) so that accurate comparisons can be made between the price and total cost of the software solution. Issues to consider in addition to acquisition of software are related maintenance, hardware, and training costs. Any increase or growth in cost may affect future infrastructure costs. 
Step \#6: Estimate Differences In Organizational Cost Savings Between Vendor Software Solutions At some point in the process, the management team should look at the functionality offerings of the remaining vendors under consideration and identify whether there are unique organizational cost saving opportunities with any of the proposed software solutions. If so, standard return-on-investment (ROI) methods can be used to estimate the savings due to that unique functionality.

Step \#7: Conduct Software Demonstrations and Select Finalists by Focusing on Functionality "Fit" Most organizations end up inviting six to ten vendors for half-day software demonstrations. Now is the time to focus more intensely on how well the vendor's software solution meets the organization's current and anticipated functional needs. Develop a scoring tool for the evaluation team to use during the software demonstrations based on the core areas of functionality laid out in the RFP. The goal in this step is to narrow the vendors down to two to three finalists, based upon both functionality and price. In most instances, organizations come to a very quick consensus about finalists at this point in the process.

Step \#8: Conduct Additional Research \& Evaluation to Make a Final Selection The last step in actually selecting a vendor is to determine what other information, if any, the organization needs to select from the finalists. Sometimes evaluation teams may need to follow-up with the vendors with some specific questions regarding functionality of the software applications that could not be covered in the demonstrations. The evaluation team may want to visit customers who are using the vendors' technology solutions to aid in the final decision making or check additional references. In some instances, price negotiation and financial due diligence can be factors differentiating between competitive vendors.

Step \#9: Contracting \& Software Implementation With final selection completed, the process moves to finalizing a contract and launching the implementation process. When moving to the contracting phase, be certain to address the following critical areas in the written contract:

- $\quad$ Linking payment terms to key milestones

- $\quad$ Ensuring that all agreed upon functional specifications are included in the software

- $\quad$ Compliance with HIPAA and other regulatory and reporting requirements

- $\quad$ Pricing for additional users and price locks or caps for a specified period of time for upgrades and support, if possible

- $\quad$ Availability of up-to-date user manuals

- $\quad$ Software escrow

The final contract should be reviewed by an attorney before it is executed. After the agreement is finalized, the next phase of the process involves planning the implementation of the proposed technology solution. Success with implementation will require a good plan, effective project management, operational changes, and close collaboration with the new vendor.

\section{CONCLUSION}

By utilizing the software vendor selection model outlined above, managers can be certain they have conducted a thorough vendor evaluation and selection process and have the confidence that they have selected the best possible software solution and the best strategic business partner. These are critical ingredients for continued operational success today and in the future.

\section{AUTHOR INFORMATION}

J. Jay Mackie, Ph.D., Associate Professor, Department of Accounting and Management Information Systems, Shippensburg University. His background includes over twenty five years of experience in both academic and business settings. Dr. Mackie has numerous publications dealing with health care, cost management and information systems and his current research interests involve information technology and strategic cost management in the health care industry. 
Monica E. Oss is the founder and chief executive officer of OPEN MINDS, a national market research and management consulting firm specializing in the health and human service field. She leads the OPEN MINDS consulting practice and serves as executive editor of its information services divisions. She is a frequent featured speaker at industry conferences and author of numerous books and articles on industry trends and strategic marketing and management issues. She serves on the advisory board of the Institute for Behavioral Health Informatics.

\section{REFERENCES}

${ }^{1}$ Social Service Spending Rises 6.9\%, 1995 To 1999: Greatest Growth In Child Care At 117\%. (2004, March). OPEN MINDS, The Behavioral Health \& Social Service Industry Analyst, 15:12, 12-13.

${ }^{2}$ Elmer, M. Colleen. (2005, November). Public Sector Behavioral Health Rose to $65 \%$ in 2001; Medicaid is $26 \%$ of Increases to Spending. OPEN MINDS, The Behavioral Health \& Social Service Industry Analyst, 17:8, 6-7.

${ }^{3}$ Juvenile Justice Spending Tops \$4.2 Billion In 1998: Residential Services Account For 66\% Of Spending. (2003, February). OPEN MINDS, The Behavioral Health \& Social Service Industry Analyst, 14:11, 7.

${ }^{4}$ Rutledge, Julie B. (2006, June). National Child Welfare Spending Increased 40\% Since 1996: Title IV-E Accounted for $50 \%$ of Federal Funding in 2004. OPEN MINDS, The Behavioral Health \& Social Service Industry Analyst, 18:3, 8 .

${ }^{5}$ Sloves, Harold. (1999, November). Special Education and Head Start Spending Reaching \$45 Billion Annually: Seven Million Children Are Recipients of These Specialized Educational Services. OPEN MINDS, The Behavioral Health \& Social Service Industry Analyst, 11:8, 6-7.

${ }^{6}$ The Fiscal Survey of States (June 2007) National Governors Association and National Association of State Budget Officers

${ }^{7}$ Oss, Monica E., Elmer, M.C., and Talbot, J. (October, 2007) The Challenges \& Opportunities for Human Service Management in the Next Decade.: A White Paper, Alliance for Children \& Families.

${ }^{8}$ Amig, Stacey, Oss, Monica E. (2001, February). New Rules for Investing in Technology. OPEN MINDS Advisor, $3: 2,1-3$.

${ }^{9}$ What Could Possibly Be Disruptive? (2007, October). OPEN MINDS, The Behavioral Health \& Social Service Industry Analyst, 19:7, 10-11.

${ }^{10}$ Jardine, Edith, Oss, Monica E. A Quick Review of Today's Technology Options. Behavioral Health Management Magazine, January/February 2001.

${ }^{11}$ Naughton-Travers, Joseph. (2003, April). Return-On-Investment For Technology: A Decision Tool For ValueBased Purchasing For Behavioral Health \& Social Service Executives. OPEN MINDS, The Behavioral Health \& Social Service Industry Analyst, 15:1, 2-4.

${ }^{12}$ KaleidaCare ROI Analysis Finds 643\% to 1,444\% Return on Technology Investment for Children's Services Organizations, OPEN MINDS On-Line News, June 13, 2005. Retrieved on December 2, 2007 from http://www.openminds.com/circlehome/eprint/omol/2005/061305roti.htm

${ }^{13}$ Naughton-Travers, Joseph P. (2001, December). Preparing For HIPAA: Complying With Transaction, Code Set \& Privacy Standards. OPEN MINDS Advisor, 3:12, 3-4. 
${ }^{14}$ CCHIT Proposes Expansion of Certification Criteria to Behavioral Health Settings, OPEN MINDS On-Line News, February 26, 2007. Retrieved on December 2, 2007 from http://www.openminds.com/circlehome/eprint/omol/2007/022607cchitbhexp.htm.

${ }^{15}$ Major, L. and Turner, M. (September/October 2003). Assessing the Information Management Requirements for Behavioral Health Providers. Journal of Healthcare Management, (48:5), pp. 323-333.

${ }^{16}$ Dabbs, III, Ben R., Lindstrom, Wayne W. (2004, August). Coming to Terms With the Information Stalemate: Closing the Management Gap in the Behavioral Health \& Social Service Field. OPEN MINDS, The Behavioral Health \& Social Service Industry Analyst, 16:5, 1, 5.

${ }^{17}$ Naughton-Travers, J., Oss, Monica E., Strategic Leverage Through Technology In Behavioral Health \& Social Services Organizations: Key Is Integrating Technology Planning With Organizational Strategy (July, 2002) OPEN MINDS, The Behavioral \& Social Service Industry Analyst

18 Brailer, David J.(July 2005). Economic Perspectives on Health Information Technology. Business Economics, July2005, Vol. 40 Issue 3, p6-14, 9p.

${ }^{19}$ Gabler, J.M. (February 2001). Linking Business Values to IT Investments. Health Management Technology, Volume 22 (2), p75-76.

${ }^{20}$ Gabler, J.M. (March 2001).IS Can Help Ensure Value from IT Investments. Managed Healthcare Executive, Volume 11 (3), p46.

${ }^{21}$ Naughton-Travers, Joseph. (2003, April). Return-On-Investment For Technology: A Decision Tool For ValueBased Purchasing For Behavioral Health \& Social Service Executives. OPEN MINDS, The Behavioral Health \& Social Service Industry Analyst, 15:1, 2-4. 


\section{NOTES}

